\title{
Conformational Study on Pheromonotropin neuropeptide using NMR and Molecular Dynamics
}

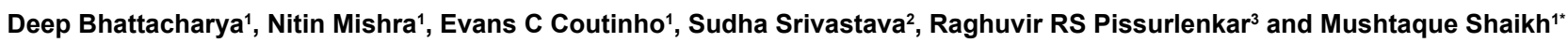

${ }^{1}$ Department of Pharmaceutical Chemistry, Bombay College of Pharmacy, Kalina, Santacruz [E], Mumbai 400098, India

${ }^{2}$ National Facility for High Field NMR, Tata Institute of Fundamental Research, Homi Bhabha Road, Navy Nagar, Colaba, Mumbai 400005, India

${ }^{3}$ Molecular Simulations Group, Department of Pharmaceutical Chemistry, Goa College of Pharmacy, Panaji Goa, 403001 India

\begin{abstract}
Pheromonotropic neuropeptide, Pseudaletia pheromonotropin, is an 18 amino acid peptide with the sequence Lys-Leu-Ser-Tyr-Asp-Asp-Lys-Val-Phe-Glu-Asn-Val-Glu-Phe-Thr-Pro-Arg-Leu which is widely distributed in female moths of Bombyx mori. This peptide is structurally related to leucopyrokinin, an insect myotropic neuropeptide, responsible for melanization and reddish coloration hormone (MRCH) activity. A combined NMR and Molecular Dynamics (MD) methods were used to fathom the conformational behaviour in water which was used as a solvent. The structure was investigated using 1D-NMR and 2D-NMR (COSY, TOCSY and ROESY) experiments. The conformation was built by constrained MD simulations using distance and dihedral restraints from NMR data in the GROMACS simulation package. The peptide predominately adopts a $\beta$-sheet structure in water.
\end{abstract}

Keywords: Pheromonotropin; Nuclear Magnetic resonance; Conformation; $\beta$-sheet; Molecular Dynamic simulations

\section{Introduction}

In lepidopteran insects, a vast number of neuropeptides are involved in regulation of various physiological events e.g. pheromone production, diuresis, myotropic activity, blood sugar level, mating, and pupal development [1]. These modifications happen in reaction to environmental conditions or to specific developmental stages [2]. In the past decades, vast studies were conducted on isolation and characterization of many insect neuropeptides. The first investigation of the function of neuropeptides in insects was carried out by Kopec in 1917 [3]. Even though a great number of conformations of insect neuropeptides have been found, there has been no report of the NMR structure of pheromonotropin. The pyrokinin/pheromone biosynthesis activating neuropeptide (PK/PBAN) multifunctional family play a pivotal part in the development in the insect life cycle [4]. Myotropins, pheromone biosynthesis activating neuropeptide (PBAN), melanization and reddish coloration hormone $(\mathrm{MRCH})$, diapause hormone and pheromonotropin are many of the neuropeptides in PK/PBAN family. The functions of these neuropeptides involves gut hormone contraction, sex hormone production, melanin biosynthesis (defense mechanism), pupariation [5-12] and have been affirmed by both (in vivo and in vitro) experiments carried on various species signifying that they do not exhibit species specificity [13]. The novel pheromonotropic neuropeptide which was extracted from the head of P. separuta larvae of Bombyx [14] bears a structural resemblance to PBAN and MRCH having a congruent sequence of Phe-Thr-ProArg-Leu at its C-terminus. MRCH, a neurohormone which regulates cuticular melanization and epidermal reddish brown pigmentation associated with morphological color change [14-18] and PBAN, a 3334 amino acid peptide having Phe-Ser-Pro-Arg-Leu- at its C-terminus regulates sex pheromone production in female moths [19-24]. In this paper, we describe the conformation of the neuropeptide obtained by NMR and molecular dynamics simulation which could contribute to the uncovering of several highly potent, selective and non-selective pheromonotropic agents that could inhibit functions exhibited by the PK/PBAN family. The NMR study was carried out in water.

\section{Experimental}

\section{Sample preparation}

The 18 amino acid peptide, Lys-Leu-Ser-Tyr-Asp-Asp-Lys-ValPhe-Glu-Asn-Val-Glu-Phe-Thr-Pro-Arg-Leu was purchased from Sigma Chemical Co., USA and was found to be in pure form when examined by NMR. $5 \mathrm{mg}$ of the peptide dissolved in $0.6 \mathrm{ml}$ of $\mathrm{H}_{2} \mathrm{O} /$ $\mathrm{D}_{2} \mathrm{O}$ (95:5) at $\mathrm{pH} 7.0$ with 3-(Trimethylsilyl) propanoic acid (TSP) was used as the internal standard, which was obtained from Stohler Isotope Chemicals, USA. At this concentration the peptide showed no aggregation.

\section{Nuclear magnetic resonance experiments}

The NMR experiments were carried out on Bruker Avance $(500,700$ and $800 \mathrm{MHz})$ FT NMR spectrometers as per requirements. The $1 \mathrm{D}$ proton spectra were studied with a spectral width of $14000 \mathrm{~Hz}$, 512 scans, and digitized with $32 \mathrm{~K}$ data points. Solvent suppression for the sample in $\mathrm{H}_{2} \mathrm{O} / \mathrm{D}_{2} \mathrm{O}$ (95:5) was accomplished using the 3-9-19 WATERGATE [25] pulse sequence. The NMR data was processed and analyzed using TopSpin (Bruker Inc.) running on a Rocks Cluster Suite 6.1. The temperature coefficients for amide protons $(\mathrm{NH})$ shifts were measured from 1D NMR spectra at temperatures ranging from $300 \mathrm{~K}$ to $320 \mathrm{~K}$.

*Corresponding author: Dr. Mushtaque Shaikh, Associate Professor (Pharmaceutical Chemistry), Department of Pharmaceutical Chemistry, Bombay College of Pharmacy, Santacruz [E], Mumbai 400098, India, Tel: 0222667 0871; E-mail: mushtaq.bcp@gmail.com

Received March 23, 2015; Accepted April 26, 2015; Published May 03, 2015

Citation: Bhattacharya D, Mishra N, Coutinho EC, Srivastava S, Pissurlenkar RRS et al. (2015) Conformational Study on Pheromonotropin neuropeptide using NMR and Molecular Dynamics. Pharm Anal Acta 6: 359. doi:10.4172/2153 2435.1000359

Copyright: (C) 2015 Bhattacharya D, et al. This is an open-access article distributed under the terms of the Creative Commons Attribution License, which permits unrestricted use, distribution, and reproduction in any medium, provided the original author and source are credited. 
Citation: Bhattacharya D, Mishra N, Coutinho EC, Srivastava S, Pissurlenkar RRS et al. (2015) Conformational Study on Pheromonotropin neuropeptide using NMR and Molecular Dynamics. Pharm Anal Acta 6: 359. doi:10.4172/2153-2435.1000359

The 2D NMR experiments included ${ }^{1} \mathrm{H}-{ }^{1} \mathrm{H}$ ROESY (Rotating frame Overhauser Effect Spectroscopy) [26] and total correlation spectroscopy (TOCSY) [27] which were used for spin system assignments. At the beginning of experiment, 32 dummy scans were collected to allow the system to reach thermal equilibrium. The residual water signal in $\mathrm{D}_{2} \mathrm{O}$ samples was suppressed by low-power pre-saturation during the relaxation delay. The spectra were acquired with a sweep width of $14000 \mathrm{~Hz}$. Typically, 512 FIDs of 2048 complex points were collected. The TOCSY experiment [27] was carried out using spin lock pulse of $150 \mathrm{~ms}$ with 512 experiments at $300 \mathrm{~K}$ and a spectral width of 9000 $\mathrm{Hz}$ for 4096 complex data points. The data were multiplied with $\pi / 4$ and $\pi / 8$ sine bell window functions along $t_{1}$ and $t_{2}$ axes prior to Fourier transformation. Coupling constants $\left({ }^{3} J_{\mathrm{NH} \alpha}\right)$ were extracted from $1 \mathrm{D}$ NMR spectra data. Identification of spin systems was done using TOCSY and ROESY sequential assignments which were made according to the methods described by Wüthrich et al. [28]. The reason ROESY spectra was recorded instead of a NOESY because there was an absence of sequential nOe's in longer mixing time $(500 \mathrm{~ms})$ of $2 \mathrm{D}$ NOESY spectrum indicating that the rotational correlation time $(\tau c)$ of the peptide was closer to the cross-over point in the relationship between $\tau c$ and nOe. It was thus necessary to obtain nOe's from $2 \mathrm{D}$ ROESY spectra as rOe's, as they are always positive in this $2 \mathrm{D}$ NMR spectrum.

\section{ROE intensities and distance restraints}

Approximate distance restraints were calculated from the ROESY cross peak intensities using the relationship $\eta_{i j} / \eta_{k l}=\left(\mathrm{r}_{k l} / \mathrm{r}_{i j}\right)^{6}$ where $\eta_{i j}$ and $\eta_{k l}$ are the rOe intensities for the atom pairs $i, j$ and $k, l$ separated by distances $r_{i j}$ and $r_{k l}$ correspondingly. The intensity of the rOe between side chain $\beta$ protons of Lys-7, $\beta$ protons of Phe- 9 and Phe- 14 with an internuclear distance of $1.73 \AA$ which was used as the reference. The distances calculated for methyl and methylene groups, were according to the rules formulated by Wüthrich et al. [28]. The strong, moderate, and weak rotating frame overhauser effect (rOe) cross-peaks were translated into distances with the lower boundary limits set at 1.9 $\AA$, and the upper boundary limits set at $2.6 \AA$ for strong, $3.1 \AA$ for medium, and $4.2 \AA$ for weak peaks [28]. The distances translated as restraints, were used with force constants that ranged from 1 to $30 \mathrm{kcal}$ $\mathrm{mol}^{-1} \mathrm{rad}^{-2}$ and a $\pm 0.5 \AA$ allowance put on the calculated distances, to represent the upper and lower bounds [28].

\section{${ }^{3} J_{\mathrm{NH} \alpha}$-dihedral angle restraints}

The ${ }^{3} J_{\mathrm{NH} \alpha}$ coupling constants values were extracted using the modified Karplus equation [29].

$$
{ }^{3} \mathrm{~J}_{\mathrm{NH} \alpha}=\mathrm{A} \operatorname{Cos}^{2}(\phi)+\mathrm{B} \operatorname{Cos}(\phi)+\mathrm{C}
$$

The values $\mathrm{A}=6.52, \mathrm{~B}=-1.76$ and $\mathrm{C}=1.60$. The coupling constants were converted to $\phi$ values, and introduced as dihedral restraints, allowing a range of $\pm 10^{\circ}$ on the calculated restraint values. Force constants in the range of 1 to $30 \mathrm{kcal} \mathrm{mol}^{-1} \mathrm{rad}^{-2}$, were used.

\section{Chemical shift index (CSI)}

The chemical shift index was developed by Wishart et al. [30]. It is calculated as a difference between the observed chemical shift and the chemical shift for that proton in the peptide when it is in a random coil structure. Residues belonging to the $\alpha$-helical region of the peptide are observed as a negative deviation from the chemical shift of random coil while residues in the $\beta$-sheet region show a positive deviation for the same.

\section{Molecular dynamics modeling}

Computational modeling technique is widely applicable for the analysis of biomolecular motion and interactions. This modelling methodology has been applied to determine the chemical, physical and biological properties of bio systems [31]. Molecular Dynamics (MD) simulation is suitable for small and large systems where individual atoms and or small clusters of atoms are involved and the phenomena influenced by the motion of individual atoms. These models explore a time scale of picoseconds $\left(10^{-12} \mathrm{~s}\right)$ to microsecond simulations. The determining equations in molecular dynamics follow classical Newtonian physics models. This method is derived from Newton's equation of motion based on the selected force fields that defines the associated forces in the biosystems. This method is popularly used as a means to model biological structures to discern events like protein folding, interaction of drug candidates with proteins and catalytic transformation.

\section{Modeling analysis methodology}

The MD simulations were performed using the GROMACS 4.6.5 package of programs [32-34], using the OPLS-AA/L all-atom force field $[35,36]$ running on Intel Xeon based 13-node high performance computing cluster operating on the Rocks Cluster Suite 6.1 to simulate the dynamics of the peptide in water under constant temperature $(300 \mathrm{~K})$ and pressure $(1 \mathrm{~atm})$ with NMR restraints. The peptide was built using the Maestro module 2014 in Schrodinger suite of program and converted to protein data bank (pdb) file for use in GROMACS simulations. The peptide was centered box of dimension of a $35 \AA$ x $35 \AA$ x $35 \AA$ PBC box filled with 28438 Simple Point Charge (SPC216) water molecules and neutralized with $3 \mathrm{Na}^{+}$ions [37]. The model was subjected to energy minimization with a combination of steepest descents and conjugate gradients ended with the Newton-Raphson method, to a gradient of $0.01 \mathrm{kcal} \mathrm{mole}^{-1} \AA$ of total of 50000 steps of 100 ps. This configuration was then constrained using LINCS [38] algorithm and equilibrated using NVT and NPT ensembles. The NVT equilibration was done with all bonds constrained and temperature coupled by a velocity rescale thermostat which is a modified Berendsen thermostat specific to GROMACS. Pressure constraint in NPT ensemble via the Parrinello-Rahmen barostat allowed the simulation cell box to change its shape accordingly. The particle mesh Ewald summation method was used for the treatment of long-range electrostatic interactions [38]. Both NVT and NPT equilibrations were carried out for 100 ps each with the temperature and pressure dynamic variations verified to ensure that the system was indeed equilibrated. The time step for the simulations was $2 f_{s}$. Vdw forces were treated using a cutoff of 1.2 $\mathrm{nm}$. Long-range electrostatic forces $(\mathrm{r}>1.2 \mathrm{~nm})$ were treated using the particle mesh Ewald method. The fully equilibrated system was used as the starting configuration for the MD production run where the peptide was constrained using distance and dihedral restraints for a total of 2500 ps. Post processing analysis tools were applied to visualize the trajectories and to quantify the configurations of the system using the Visual Molecular Dynamics (VMD) software and GROMACS package tools.

\section{Results and Discussion}

\section{NMR structure of pheromonotropin}

The 1D NMR spectrum of the peptide was well resolved and all the $\mathrm{NH}$ peaks except the terminal Lys were observed between 6.3 to 8.5 ppm. As a rule of thumb, amino acids in the peptide were identified by the pattern of the TOCSY cross peaks according to the spin system 
Citation: Bhattacharya D, Mishra N, Coutinho EC, Srivastava S, Pissurlenkar RRS et al. (2015) Conformational Study on Pheromonotropin neuropeptide using NMR and Molecular Dynamics. Pharm Anal Acta 6: 359. doi:10.4172/2153-2435.1000359

of each amino acid in relation to the actual chemical shift values [28]. The unique spin systems of Thr $\left(\mathrm{A}_{3} \mathrm{MX}\right)$ and Glu $[\mathrm{AM}(\mathrm{PT}) \mathrm{X}]$ were distinctly identified from the TOCSY spectra, four AMX spin systems were assigned to one Asn, two Asp residues and one Ser residue or long side-chain spin systems in which further scalar coupling to more peripheral protons was observed (i.e. Glu and Arg). The Asp residue was then identified based on the fact that its $\delta$ protons resonate downfield compared to those of Asn residues. The Pro residue was assigned from the typical chemical shift values of its $\delta$ protons $\left(\mathrm{C}_{\alpha} \mathrm{H}\right.$ and $\mathrm{C}_{\delta} \mathrm{H}$ signals). The unique spin systems of $\mathrm{Val}\left(\mathrm{A}_{3} \mathrm{~B}_{3} \mathrm{MX}\right)$ and $\mathrm{Thr}$ ( $\left.\mathrm{A}_{3} \mathrm{MX}\right)$ help to identify them unambiguously. The two Lys residues were ascertained from the typical spin system $\left[\mathrm{A}_{2}\left(\mathrm{~F}_{2} \mathrm{~T}_{2}\right) \mathrm{MPX}\right]$ seen in the TOCSY spectrum. The aromatic AMX spin system, Phe, was identified from the observation of nOe's from the $\mathrm{H} \beta$ protons observed to the nearest aromatic ring protons in the $2 \mathrm{D}$ ROESY spectrum. Once all the amino acids were identified a sequential self-walk assignments was done based on 2D TOCSY and 2D ROESY data shown as in Figure 1 . The rOe cross-peaks corresponding to sequential $\mathrm{d}_{\alpha \mathrm{N}}$ distance led to the sequence-specific ${ }^{1} \mathrm{H}_{-}^{1} \mathrm{H}$ resonance assignments Figure 2 of all the amino acids from the $\mathrm{N}$ to the $\mathrm{C}$ terminal of the peptide except between Thr-15 and Pro-16, since Pro-16 since it has no HN proton. The rOe observed between $\mathrm{H} \delta$ protons of Pro-16 and $\mathrm{Ha}$ of Thr-15 helped in assigning the Thr-15 and-Pro-16 in the sequential walk. The sequential walk of the peptide sequence shown in Figure 1 with overlapping TOCSY and ROESY spectra's.

Temperature coefficients of $\mathrm{NH}$ chemical shifts have been calculated from 1D spectra recorded in the temperature range of 300 to $320 \mathrm{~K}$. Values below $(-\Delta \delta / \Delta \mathrm{T}) 3.00 \mathrm{ppb} / \mathrm{K}$ are indicative of a strong intramolecular $\mathrm{H}$-bonds and values between $3.0-5.0 \mathrm{ppb} / \mathrm{K}$ are characteristic of dynamic equilibrium between intramolecularly hydrogen bonded form which are exposed to the solvent [39]. The values obtained fall in the range of $6-8.9 \mathrm{ppb} / \mathrm{K}$ indicating that the $\mathrm{NH}$ protons are freely exposed to the solvent. The results from the temperature coefficients of amide protons of the peptide KLSYDDKVFENVEFTPNL indicate that no amide proton (HN) is involved in hydrogen bonding Figure 3.

Positive CSI values for the $\mathrm{C}_{\alpha} \mathrm{H}$ protons of the peptide and lack of significant rOe's (long range $\mathrm{d}_{\mathrm{NN}}$ ) and relatively high amide temperature coefficients for almost all residues, indicate a $\beta$-sheet or random coil like structure Figure 4 . The ${ }^{3} \mathrm{~J}_{\mathrm{NH} a}$ coupling constant is a function of the dihedral angle $\phi$ calculated using the Karplus equation which is helpful in identifying different peptide conformations [28]. The perceived ${ }^{3} \mathrm{~J}_{\mathrm{NH} \alpha}$ coupling constants for the peptide are higher than $7.0 \mathrm{~Hz}$ and were characteristic of a predominantly extended backbone conformation. Overall, 58 meaningful distance restraints could be obtained along with 15 dihedral angle restraints were incorporated in the restrained molecular dynamic simulation carried out for $2500 \mathrm{ps.}$ The backbone torsion angle $(\phi, \Psi)$ averaged over the entire trajectory for the peptide is indicative of a very good homogeneity of the simulated structures showing a trend for a $\beta$-sheet. The structures were classified as converged consistent with the NMR data and maintained correct stereochemistry. All converged structures had few NOE constraints violations more than $0.3 \AA$. The superposition of the best lowestenergy NMR structures for the peptide is depicted in Figures 5 and 6. The average pairwise RMSD calculated for is 0.35 A. Figures 7 and 8 . Structural statistics tabulated in Table 1 and 2.

Overall, the peptide KLSYDDKVFENVEFTPNL had a predominantly extended backbone conformation ( $\beta$-sheet like) in $\mathrm{H}_{2} \mathrm{O}$ at $300 \mathrm{~K}$.

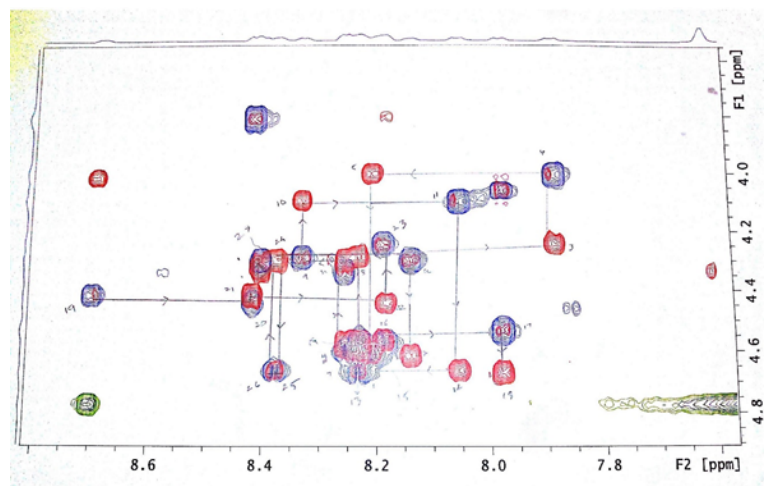

Figure 1: Fingerprint region of the TOCSY and ROESY spectrum of Pheromonotropin in $\mathrm{H}_{2} \mathrm{O}$ showing the sequential self-walk. (Blue peaksTOCSY and Red peaks- ROESY)

TOCY and Red peaks-ROESY)

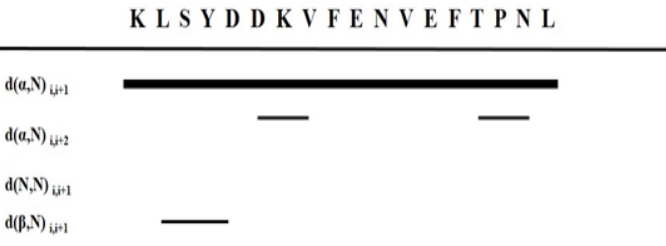

Figure 2: Connectivities of Pheromonotropin in $\mathrm{H}_{2} \mathrm{O}$

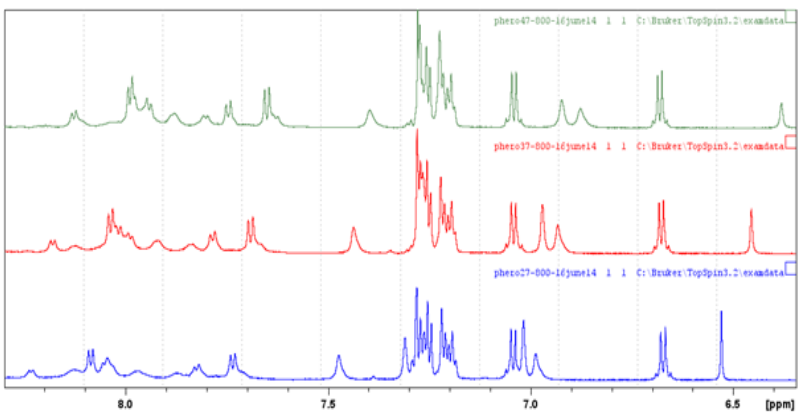

Figure 3: Temperature-dependent $1 \mathrm{D}^{1} \mathrm{H} N \mathrm{NR}$ spectra of Pheromonotropin in $\mathrm{H}_{2} \mathrm{O}$

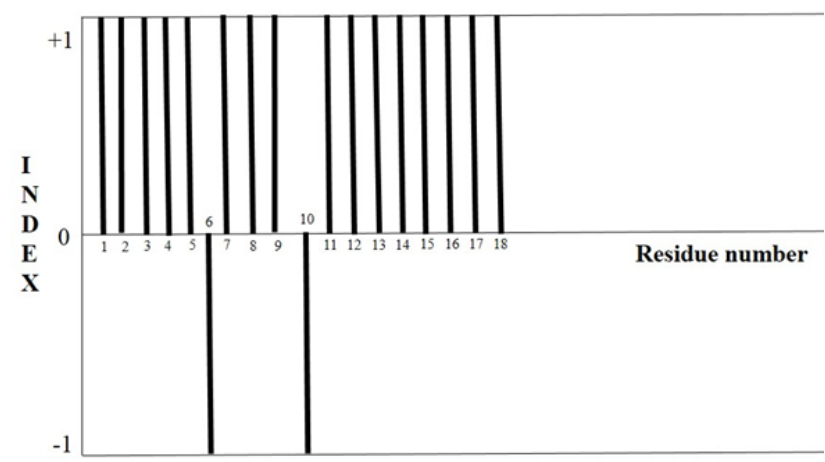

Figure 4: ${ }^{1} \mathrm{H}$ chemical shift index (CSI) for Pheromonotropin 
Citation: Bhattacharya D, Mishra N, Coutinho EC, Srivastava S, Pissurlenkar RRS et al. (2015) Conformational Study on Pheromonotropin neuropeptide using NMR and Molecular Dynamics. Pharm Anal Acta 6: 359. doi:10.4172/2153-2435.1000359

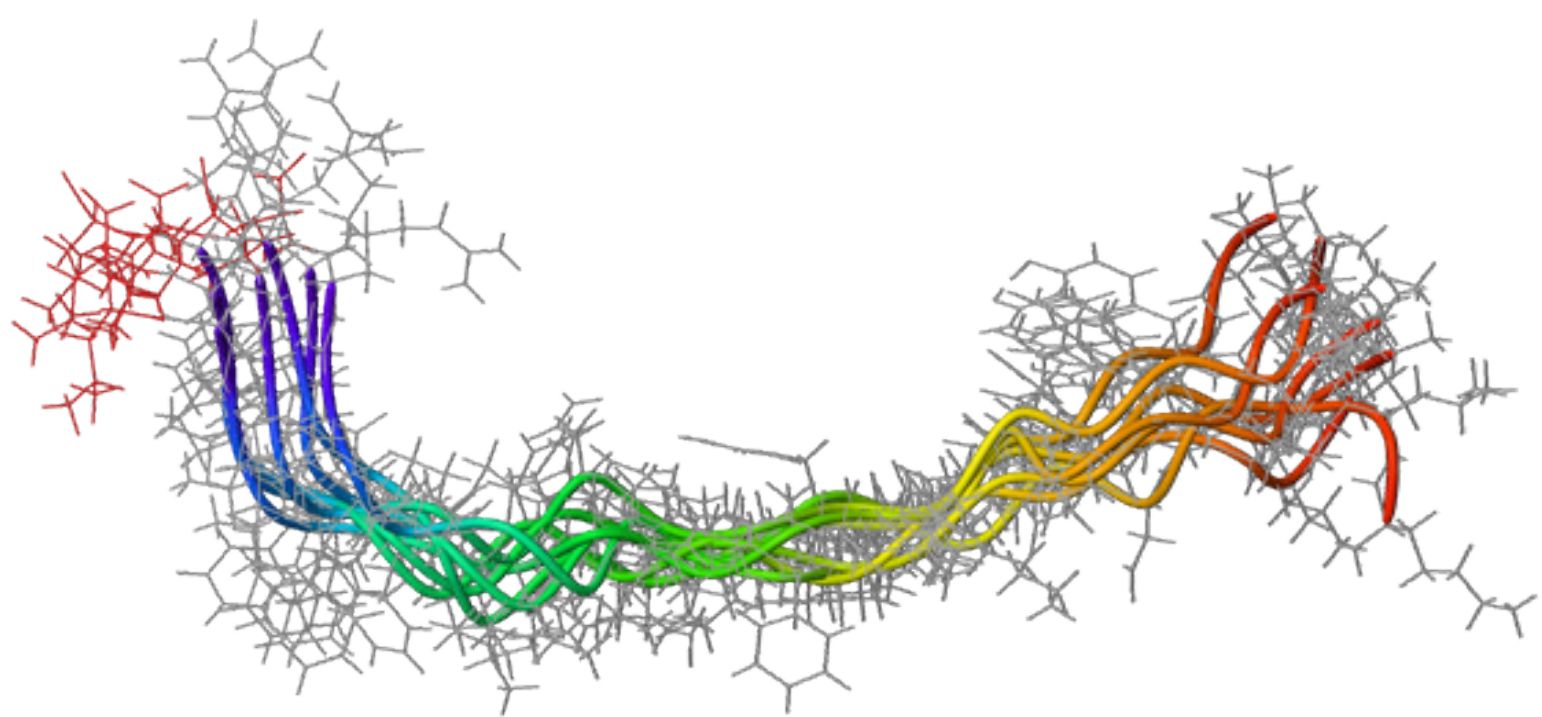

Figure 5: 6-Best-fit backbone superposition for the best NMR structures resulting from NMR-restrained Molecular dynamics calculations of Pheromonotropin with GROMACS

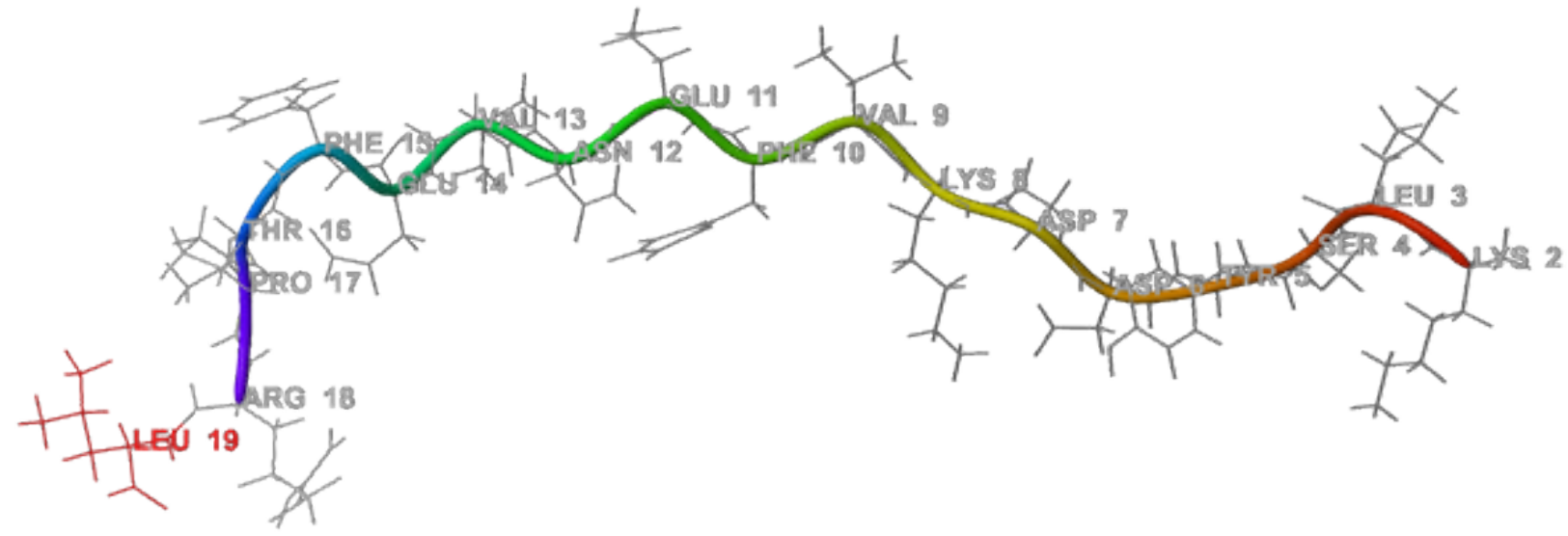

Figure 6: The NMR derived structure of Pheromonotropin in $\mathrm{H}_{2} \mathrm{O}$.

\section{Secondary structure}

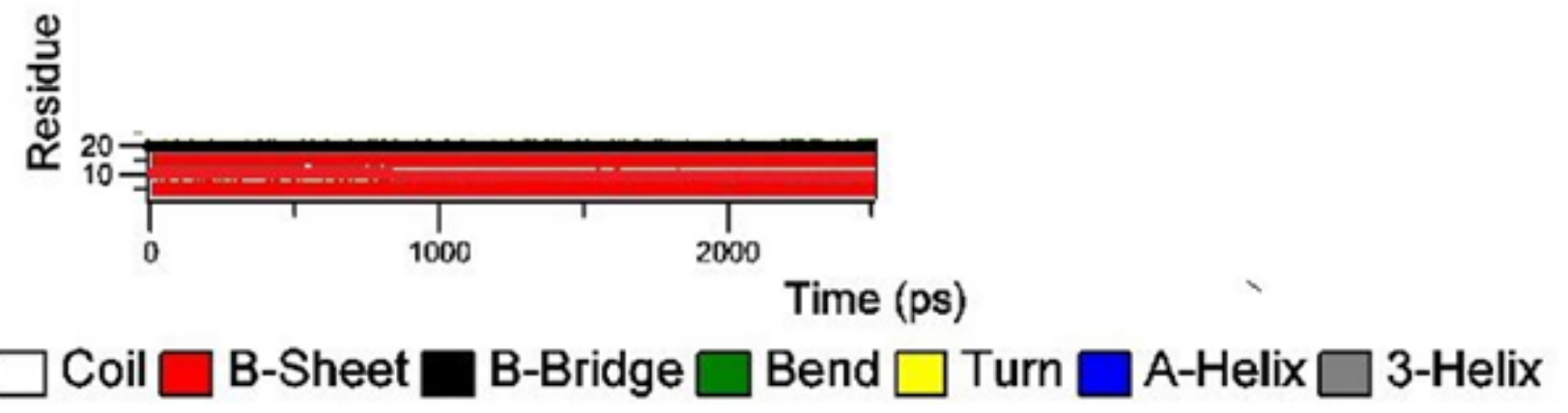

Figure 7: Using dssp program in GROMACS to depict the secondary structure of Pheromonotropin resulting from NMR-restrained Molecular dynamics. 
Citation: Bhattacharya D, Mishra N, Coutinho EC, Srivastava S, Pissurlenkar RRS et al. (2015) Conformational Study on Pheromonotropin neuropeptide using NMR and Molecular Dynamics. Pharm Anal Acta 6: 359. doi:10.4172/2153-2435.1000359

\section{Ramachandran Plot}

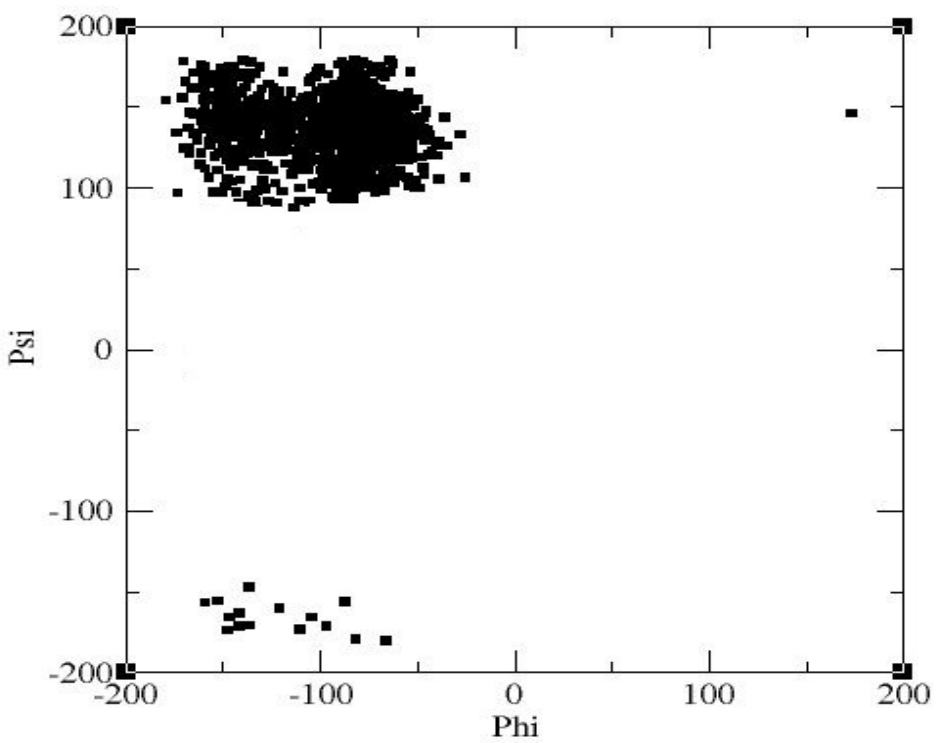

Figure 8: Ramachandran plot for the ensemble of best NMR structures from restrained molecular dynamics.

\begin{tabular}{|c|c|}
\hline \multicolumn{2}{|c|}{ Distance restraints } \\
\hline Intra-residue & 40 \\
\hline Inter-residue & 18 \\
\hline Sequential & 17 \\
\hline NOE violations $>0.3 \mathrm{~A}^{\circ}$ & 4 \\
\hline \multicolumn{2}{|c|}{$\begin{array}{l}\text { RMSD of backbone atoms of the ensemble against } \\
\text { global minimum structure }\end{array}$} \\
\hline Maximum & 0.95 \\
\hline Minimum & 0.07 \\
\hline Average & 0.35 \\
\hline
\end{tabular}

Table 1: Structural statistics of Pheromonotropin in 95:5 $\mathrm{H}_{2} \mathrm{O}: \mathrm{D}_{2}$ Omixture

\begin{tabular}{|c|c|c|c|c|c|c|}
\hline Residue & NH & $\mathbf{H}_{\alpha}$ & $\mathrm{H}_{\beta}$ & Others & $\begin{array}{l}\text { Temp. coefficient } \\
-\Delta \delta / \Delta T(p p b / K)\end{array}$ & ${ }^{3} \mathrm{~J}_{\mathrm{NH \alpha}}(\mathrm{Hz})$ \\
\hline $\mathrm{K} 1$ & - & 4.38 & $1.86,1.77$ & $\begin{array}{l}\mathrm{yCH}_{2}-1.48 \\
\mathrm{\gamma CH}_{2}-2.33 \\
\delta \mathrm{CH}_{2}-1.65 \\
\varepsilon \mathrm{CH}_{2}-3.102\end{array}$ & -4.3 & - \\
\hline L2 & 8.420 & 4.407 & 1.589 & $\begin{array}{c}\mathrm{yH}-1.469 \\
\delta \mathrm{CH}_{3}-0.9,0.92\end{array}$ & -6.3 & 7.82 \\
\hline S3 & 8.420 & 4.24 & 3.811 & & -6.2 & 8.2 \\
\hline Y4 & 8.189 & 4.245 & $3.041,2.947$ & $\begin{array}{l}3,5 \mathrm{H}-7.21 \\
2,6 \mathrm{H}-7.10\end{array}$ & -5.9 & 8.4 \\
\hline D5 & 8.364 & 4.663 & $2.823,2.744$ & & -5.3 & 7.62 \\
\hline D6 & 8.381 & 4.668 & $2.828,2.734$ & & -6.1 & 8.012 \\
\hline
\end{tabular}


Citation: Bhattacharya D, Mishra N, Coutinho EC, Srivastava S, Pissurlenkar RRS et al. (2015) Conformational Study on Pheromonotropin neuropeptide using NMR and Molecular Dynamics. Pharm Anal Acta 6: 359. doi:10.4172/2153-2435.1000359

Page 6 of 7

\begin{tabular}{|c|c|c|c|c|c|c|}
\hline K7 & 8.406 & 4.414 & $1.828,1.769$ & $\begin{array}{l}\gamma \mathrm{YH}_{2}-1.56 \\
\mathrm{yCH}_{2}-2.36 \\
\delta \mathrm{CH}_{2}-1.69 \\
\varepsilon \mathrm{CH}_{2}-3.202\end{array}$ & -7.2 & 9.2 \\
\hline V8 & 7.885 & 3.996 & 1.968 & $\mathrm{YCH}_{3}-0.842,0.784$ & -7.9 & 8.9 \\
\hline F9 & 8.206 & 4.612 & $3.131,2.996$ & $\begin{array}{c}2,6 \mathrm{H} 7.30 \\
4 \mathrm{H} 7.27 \\
3,5 \text { H } 7.19\end{array}$ & -5.5 & 6.9 \\
\hline E10 & 8.229 & 4.670 & $2.749,2.613$ & $\mathrm{yCH}_{2}-2.40$ & -7.2 & 8.8 \\
\hline N11 & 8.328 & 4.294 & $2.306,2.233$ & $\mathrm{YNH}_{2}-7.09$ & -4.2 & 7.3 \\
\hline V12 & 8.051 & 4.090 & 2.063 & $\mathrm{yCH}_{3}-0.893$ & -7.9 & 9.04 \\
\hline E13 & 8.259 & 4.649 & $2.23,2.53$ & $\mathrm{yCH}_{2}-2.742,2.626$ & -6.8 & 7.87 \\
\hline F14 & 8.225 & 4.544 & $3.104,3.052$ & $\begin{array}{c}2,6 \mathrm{H} 7.25 \\
4 \mathrm{H} 7.20 \\
3,5 \mathrm{H} 7.11\end{array}$ & -5.9 & 8.2 \\
\hline T15 & 7.975 & 4.540 & 4.054 & $\mathrm{yCH}_{3}-1.178$ & -6.6 & 7.63 \\
\hline $\mathrm{P} 16$ & - & 4.36 & $2.02,1.91$ & $\begin{array}{c}\mathrm{yH} 1.83 \\
\delta \mathrm{H} 3.56,3.67\end{array}$ & - & - \\
\hline N17 & 8.327 & 4.289 & $2.302,2.239$ & $\begin{array}{c}\mathrm{YCH}_{2}-1.945 \\
\delta \mathrm{CH}_{2}-3.30 \\
\mathrm{NH}-7.19\end{array}$ & -5.6 & 8.5 \\
\hline L18 & 8.258 & 4.637 & 1.642 & $\begin{array}{c}\gamma \mathrm{H} 1.641 \\
\delta \mathrm{CH} 3-0.925,0.870\end{array}$ & -5.2 & 8.1 \\
\hline
\end{tabular}

Table 2: Observed values for Pheromonotropin in water.

\section{Conclusion}

Computational modeling and simulations based on molecular dynamics provides an effective means to understand the structure and dynamics of biomolecules. Using the GROMACS molecular dynamics package, we investigated, the conformation of the insect neuropeptide pheromonotropin based on NMR data. The conformation using NMR data in conjuction and molecular dynamics simulations in water yielded a $\beta$-sheet. The dynamical simulation results were visually and quantitatively analyzed for the conformation. The analysis and visualization of the generated peptide structure can give us meaningful insights into its pharmacological/physiological role aiding rational drug design for peptidomimetics and also unravelling other unknown neuropeptides in the (PK/PBAN) multifunctional family.

\section{Acknowledgment}

We acknowledge the NMR facilities provided by the National Facility for High Field NMR located at Tata Institute of Fundamental Research, Mumbai and the computational and infrastructural facilities provided by Department of Science and Technology, New Delhi through their SERB program (SR/FST/LSI-163/2003; SR/ SO/HS-0117/2012) and Council of Scientific and Industrial Research, New Delhi (01/2399/10/EMRII).

\section{References}

1. Holman GM, Nachman RJ, Wright MS (1990) Insect neuropeptides. Annu Rev Entomol 35: 201-217.

2. Raabe M (1989) Recent Developments in Insect Neurohormones, Springer.
3. Holman GM, Cook BJ, Nachman RJ (1986) Primary structure and synthesis of a blocked myotropic neuropeptide isolated from the cockroach, Leucophaea maderae. Comp Biochem Physiol C 85: 219-224.

4. Nachman RJ, Holman GM, Cook BJ (1986) Active fragments and analogs of the insect neuropeptide leucopyrokinin: structure-function studies. Biochem Biophys Res Commun 137: 936-942.

5. Schoofs L, Holman GM, Hayes TK, Nachman RJ, De Loof A (1991) Isolation, primary structure, and synthesis of locustapyrokinin: a myotropic peptide of Locusta migratoria. Gen Comp Endocrinol 81: 97-104.

6. Imai KKT, Nakazawa Y, Komiya T, Isobe M, Koga K, et al. (1991) Isolation and structure of diapause hormone of the silkworm Bombyx mori. Proc Jpn Acad Ser B Phys Biol Sci 67: 98-101.

7. Nachman RJ, Holman GM, Schoofs L, Yamashita O (1993) Silkworm diapause induction activity of myotropic pyrokinin (FXPRLamide) insect neuropeptides. Peptides 14: 1043-1048.

8. Nachman RJ ZJ, Holman GM, Hayes TK (1997) Pupariation acceleration in fleshfly (Sarcophaga bullata) larvae by the pyrokinin/PBAN neuropeptide family-structure-activity relationships. Ann NY Acad Sci 814: 73-79.

9. Xu WH, Denlinger DL (2003) Molecular characterization of prothoracicotropic hormone and diapause hormone in Heliothis virescens during diapause, and a new role for diapause hormone. Insect Mol Biol 12: 509-516.

10. Xu WH, Denlinger DL (2003) Molecular characterization of prothoracicotropic hormone and diapause hormone in Heliothis virescens during diapause, and a new role for diapause hormone. Insect Mol Biol 12: 509-516.

11. Zd'árek J, Myska P, Zemek R, Nachman RJ (2002) Mode of action of an insect neuropeptide leucopyrokinin (LPK) on pupariation in fleshfly (Sarcophaga bullata) larvae (Diptera: Sarcophagidae). J Insect Physiol 48: 951-959. 
Citation: Bhattacharya D, Mishra N, Coutinho EC, Srivastava S, Pissurlenkar RRS et al. (2015) Conformational Study on Pheromonotropin neuropeptide using NMR and Molecular Dynamics. Pharm Anal Acta 6: 359. doi:10.4172/2153-2435.1000359

12. Matsumoto S, Kitamura A, Nagasawa H, Kataoka H, Orikasa C (1990) Functional diversity of a neurohormone produced by the subesophagea ganglion: molecular identity of melanization and reddish coloration hormone and pheromone biosynthesis activating neuropeptide. Insect Physiol 36: 427432

13. Zhao JY, Xu WH, Kang L (2004) Functional analysis of the SGNP I in the pupal diapause of the oriental tobacco budworm, Helicoverpa assulta (Lepidoptera: Noctuidae). Regul Pept 118: 25-31.

14. Matsumoto S, Fonagy A, Kurihara M, Uchiumi K, Nagamine T (1992) Isolation and primary structure of a novel pheromonotropic neuropeptide structurally related to leucopyrokinin from the armyworm larvae, Pseudaletia separate. Biochem biophys Res Commun 182: 534-539.

15. Nobuo Ogura (1975) Hormonal control of larval colouration in the armyworm Leucania separata. J insect Physiol 21: 559-576.

16. Hiruma K, Matsumoto S, Isogai A, Suzuki A (1984) Control of ommochrome synthesis by both juvenile hormone and melanization hormone in the cabbage armyworm, Mamestra brassicae. J camp Physiol B 154: 13-21.

17. Masayuki Moritaa, Makoto Hatakoshi, Sumio Tojo (1988) Hormonal control of cuticular melanization in the common cutworm, Spodoptera litura. J Insect Physiol 34: 751-758.

18. Matsumoto S, Isogai A, Suzuki A (1988) Purification and characterization of melanization and reddish coloration hormone $(\mathrm{MRCH})$ in lepidopteran insects. Prog Clin Biol Res 256: 437-451.

19. Matsumoto S, Isogai A, Suzuki A (1988) Purification and characterization of melanization and reddish coloration hormone $(\mathrm{MRCH})$ in lepidopteran insects. Prog Clin Biol Res 256: 437-451.

20. Raina AK, Klun JA (1984) Brain factor control of sex pheromone production in the female corn earworm moth. Science 225: 531-533.

21. Ando TAR, Uchiyama M, Nagasawa H, Moue T (1988) Pheromone biosynthesis activating neuropeptide hormone in heads of the silkworm moth. Agric- \&ok Chem 52: 881-883.

22. Tatsuki S, Usui K, Arai K, Kurihara M, Uchiumi K (1985) Hormone-like substance present in the cephalic organs of the female moth, Chile suppressalis (Walker) (Lepidoptera: Pyralidae) and controlling sex pheromone production. Jap J appi Ent Zool 29: 265-269.

23. Zhao CH, Li Q, Gao W (2002) Stimulation of sex pheromone production by PBAN-like substance in the pine caterpillar moth, Dendrolimus punctatus (Lepidoptera: Lasiocampidae). Arch Insect Biochem Physiol 49: 137-148.

24. Kitamura A, Nagasawa $H$, Kataoka $H$, Inoue $T$, Matsumoto $S$, et al. (1989) Amino acid sequence of pheromone-biosynthesis-activating neuropeptide (PBAN) of the silkworm, Bombyx mori. Biochem Biophys Res Commun 163 $520-526$.
25. Kitamura A, Nagasawa $H$, Kataoka H, Ando T, Suzuki A (1990) Amino acid sequence of pheromone biosynthesis activating neuropeptide-II (PBAN-II) of the silkmoth, Bombyx mori. Agric Biol Chem 54: 2495-2497.

26. Kuniyoshi H, Nagasawa KA, Chuman H, Shimazaki T (1991) Structure-activity relationship of pheromone biosynthesis activating neuropeptide (PBAN) from the silkworm, Bombyx mori. Peptide Chemistry 1990 (Ed Shimonishi Y) 251 254.

27. Sklenar V PM, Leppik K, Saudek V (1993) Gradient-tailored water suppression for $1 \mathrm{H}-15 \mathrm{~N}$ HSQCJ experiments optimized to retain full sensitivity. J Magn Reson A 102: 241-245.

28. (1984) W. B-BAASRLLJMWCDJR. Journal of the American Chemical Socie 104: 811-813.

29. Ad Bax, Donald G Davis (1985) MLEV-17 based two-dimensional homonuclear magnetization transfer spectroscopy. J Magn Reson A 65: 355-360.

30. Wuthrich K (1986) NMR of Proteins and Nucleic Acids, Wiley, New York.

31. Vuister GW, Bax A (1993) Quantitative J correlation: a new approach for measuring homonuclear three-bond $\mathrm{J}(\mathrm{HNHa})$ coupling constants in 15 $\mathrm{N}$-enriched proteins. J Am Chem Soc 115: 7772-7777.

32. Wishart DS, Sykes BD, Richards FM (1992) The chemical shift index: a fast and simple method for the assignment of protein secondary structure through NMR spectroscopy. Biochemistry 31: 1647-1651.

33. Auffinger $P$, Westhof $E$ (1998) Simulations of the molecular dynamics of nucleic acids. Curr Opin Struct Biol 8: 227-236.

34. Auffinger $P$, Westhof $E$ (1998) Simulations of the molecular dynamics of nucleic acids. Curr Opin Struct Biol 8: 227-236.

35. Hess B, Kutzner c, van der Spoel D, Lindahl E (2008) GROMACS 4: Algorithms for highly efficient, load-balanced, and scalable molecular simulation. J Chem Theory Comput 4: 435-447.

36. Van Der Spoel D, Lindahl E, Hess B, Groenhof G, Mark AE, et al. (2005) GROMACS: fast, flexible, and free. J Comput Chem 26: 1701-1718.

37. Berendsen HJC, van der Spoel D, van Drunen R (1995) GROMACS: A message-passing parallel molecular dynamics implementation. Comp Phys Comm 91: 43-56.

38. Jorgensen DSM, Tirado-Rives J (1996) J Am Chem Soc 116: 11225-11236.

39. Kaminski RAF, Tirado-Rives J, Jorgensen WL (2001) J Phys Chem B 105 6474-6487. 